\title{
Dynamic range enhancement and amplitude regeneration in single pump fibre optic parametric amplifiers using DPSK modulation
}

Peucheret, Christophe; Lorenzen, Michael Rodas; Seoane, Jorge; Noordegraaf, Danny; Nielsen, Carsten Vandel; Grüner-Nielsen, Lars; Rottwitt, Karsten

Published in:

34th European Conference on Optical Communication

Link to article, DOI:

10.1109/ECOC.2008.4729252

Publication date:

2008

Document Version

Publisher's PDF, also known as Version of record

Link back to DTU Orbit

Citation (APA):

Peucheret, C., Lorenzen, M. R., Seoane, J., Noordegraaf, D., Nielsen, C. V., Grüner-Nielsen, L., \& Rottwitt, K. (2008). Dynamic range enhancement and amplitude regeneration in single pump fibre optic parametric amplifiers using DPSK modulation. In 34th European Conference on Optical Communication: 21st to 25th September (pp. 1-2). IEEE. https://doi.org/10.1109/ECOC.2008.4729252

\section{General rights}

Copyright and moral rights for the publications made accessible in the public portal are retained by the authors and/or other copyright owners and it is a condition of accessing publications that users recognise and abide by the legal requirements associated with these rights.

- Users may download and print one copy of any publication from the public portal for the purpose of private study or research.

- You may not further distribute the material or use it for any profit-making activity or commercial gain

- You may freely distribute the URL identifying the publication in the public portal 


\title{
Dynamic Range Enhancement and Amplitude Regeneration in Single Pump Fibre Optic Parametric Amplifiers using DPSK Modulation
}

Christophe Peucheret (1), Michael Lorenzen (1), Jorge Seoane (1), Danny Noordegraaf (1),

Carsten Vandel Nielsen (1), Lars Grüner-Nielsen (2) and Karsten Rottwitt (1)

1 : Department of Photonics Engineering, Technical University of Denmark, DK-2800 Kgs. Lyngby, Denmark, cp@com.dtu.dk

2 : OFS Fitel Denmark ApS, Priorparken 680, DK-2605 Brøndby, Denmark

\begin{abstract}
Input power dynamic range enhancement and amplitude regeneration of highly distorted signals are demonstrated experimentally for 40 Gbit/s RZ-DPSK in a single-pump fibre parametric amplifier with $22 \mathrm{~dB}$ smallsignal gain.
\end{abstract}

\section{Introduction}

Nonlinear phase noise (NPN) is one of the most severe impairments in return-to-zero differential phase shift keying (RZ-DPSK) transmission. Limiting the intensity fluctuations of the signal has been shown to reduce the accumulation of NPN, hence the need for all optical intensity fluctuation reduction techniques that are furthermore transparent to the phase [1]. Gain saturation in a fibre optic parametric amplifier (FOPA) enables intensity equalisation of on-off keying (OOK) signals [2], and signal saturation induced by pump depletion due to the four-wave mixing (FWM) process has been investigated numerically for DPSK signals [1]. Preliminary experimental results based on amplitude histograms have also been reported in the non-amplifying regime and for low duty cycle pulses [3]. Recently, DPSK signal impairments in dual [4] and single pump [5] FOPA have been studied and the saturation of parametric gain has been exploited for OOK and DPSK amplitude regeneration in a Kerr switch relying on polarisation rotation [6]. However, to date, no confirmation of the regenerative behaviour of single-pump FOPA based on unambiguous BER measurements has been reported in the literature for DPSK modulation.

In this work, we experimentally show that the input power dynamic range of a single pump (amplifying) FOPA can be significantly enhanced for RZ-DPSK modulation as compared to RZ-OOK. Furthermore, we exploit this effect to demonstrate successful amplitude regeneration of a highly distorted $40 \mathrm{Gbit} / \mathrm{s}$ RZ-DPSK signal in a FOPA with over $20 \mathrm{~dB}$ gain.

\section{Experimental set-up}

The experimental set-up is depicted in Fig. 1. A $40 \mathrm{Gbit} / \mathrm{s} 33 \%$ RZ-OOK or RZ-DPSK signal is generated from a continuous wave (CW) laser using a Mach-Zehnder modulator (MZM) pulse carver driven by a $20 \mathrm{GHz}$ sinusoidal signal followed by a data modulator driven with a $2^{31}-1$ pseudo random binary (PRBS) sequence. The modulation format is selected by a proper choice of the bias and peak-to-peak voltage of the data signal applied to the second MZM.

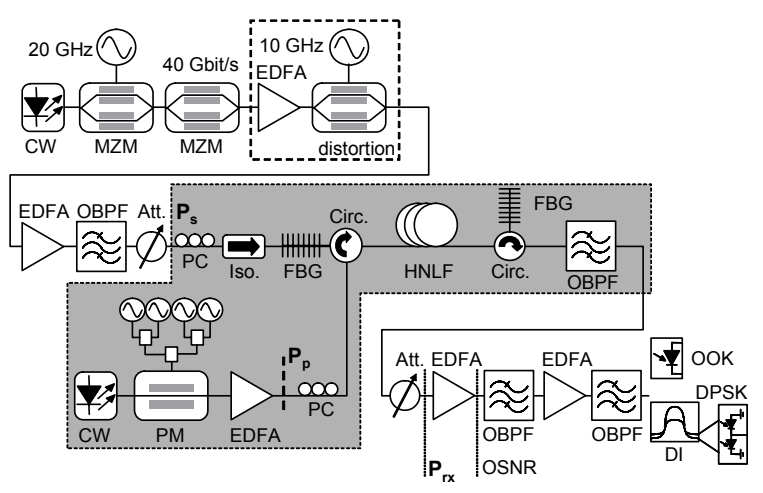

Figure 1: Experimental set-up.

The signal input power to the FOPA is then adjusted using an erbium doped fibre amplifier (EDFA) followed by an optical bandpass filter (OBPF) and a variable attenuator. The pump signal is derived from a CW laser amplified up to $30.5 \mathrm{dBm}$ in an EDFA. In order to suppress stimulated Brillouin scattering, the pump is phase modulated using 4 sinusoidal tones at 123, 600, 1000 and $2350 \mathrm{MHz}$. Signal and pump are coupled into the $500 \mathrm{~m}$ highly nonlinear fibre (HNLF) using a fibre Bragg grating (FBG) and a circulator. The fibre has zero dispersion at $1560.5 \mathrm{~nm}$, a dispersion slope equal to $0.015 \mathrm{ps} /\left(\mathrm{nm}^{2} \cdot \mathrm{km}\right)$, an attenuation of $0.74 \mathrm{~dB} / \mathrm{km}$ and a nonlinear coefficient of $11.5 \mathrm{~W}^{-1} \cdot \mathrm{km}^{-1}$. At the HNLF output, the signal wavelength is selected using another FBG followed by an OBPF and is input to a receiver consisting of an optical preamplifier and a $40 \mathrm{GHz}$ photodiode (in the case of OOK) or a delay interferometer (DI) followed by a balanced detector (in the case of DPSK).

The FOPA was characterised for a pump wavelength of $1564.1 \mathrm{~nm}$, as shown in Fig. 2. The on-off gain was measured at the HLNF output and peaks around $1549.5 \mathrm{~nm}$ and $1548.5 \mathrm{~nm}$ for 29.5 and $30.5 \mathrm{dBm}$ pump power, respectively. Due to the availability of FBG at that wavelength, the signal was tuned to $1546 \mathrm{~nm}$ in the experiments. The FOPA exhibits clear saturation behaviour with small signal gains of 16 and $22 \mathrm{~dB}$ and input saturation powers of 13 and $9.5 \mathrm{dBm}$ for 29.5 and $30.5 \mathrm{dBm}$ pump power, respectively. 

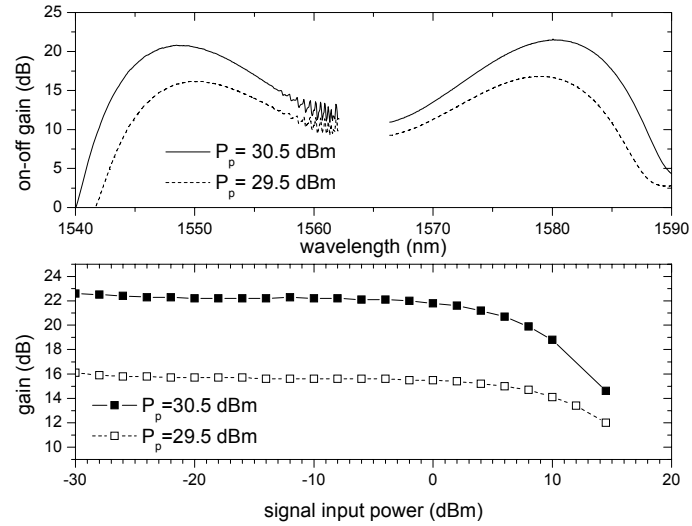

Figure 2: FOPA on-off gain spectrum (top) and gain as a function of signal input power (bottom).

\section{Results and discussion}

The optical signal-to-noise ratio (OSNR, measured in $0.1 \mathrm{~nm}$ bandwidth) penalty compared to back-to-back was measured at a bit-error-ratio of $10^{-9}$ as a function of signal input power to the FOPA (Fig. 3). The limitation of the performance of the amplifier by poor OSNR and nonlinearities at low and high input power, respectively, is clearly observed in the case of RZOOK. The higher penalty observed for $30.5 \mathrm{dBm}$ pump power is due to enhanced self-phase modulation (SPM) at high path average power through the HNLF. However, the inherent resilience of RZ-DPSK to SPM, which is due to its periodic power envelope, results in lower penalty and larger high input power tolerance than for RZ-OOK. The onset of nonlinear degradation had actually not been reached with the maximum value of signal power that was available in our experiment (15 dBm).
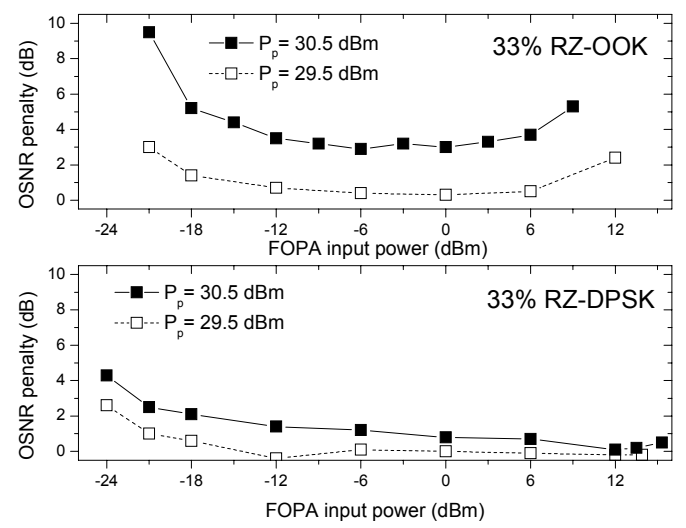

Figure 3: OSNR penalty as a function of FOPA input signal power for OOK and DPSK modulation.

This enhanced dynamic range is exploited to demonstrate amplitude regeneration of an RZ-DPSK signal. For this purpose, the signal is distorted by an extra MZM driven by a $10 \mathrm{GHz}$ sinusoidal signal and input to the FOPA with $13.4 \mathrm{dBm}$ average power in order to experience gain saturation. The distorted input signal is shown in Fig. 4-a). This distortion results in $3.5 \mathrm{~dB}$ penalty compared to a back-to-back undistorted RZ-DPSK signal and $4.1 \mathrm{~dB}$ penalty after propagation through the FOPA with the pump turned off. The optical waveform and the single-ended detected signal after demodulation (Fig. 4-c and b, respectively) clearly show severe intensity fluctuations. However, when the $30.5 \mathrm{dBm}$ pump is turned on, those amplitude fluctuations are suppressed (Fig. 4-d, e). Accordingly, the penalty after the FOPA is reduced to $0.2 \mathrm{~dB}$, clearly demonstrating its regenerative behaviour. For the same amount of intensity distortion and same pump power, even though Fig. 5 suggests that the intensity of an RZ-OOK signal can partly be equalised by FOPA saturation, the high SPM degradation prevents error-free detection of the signal.
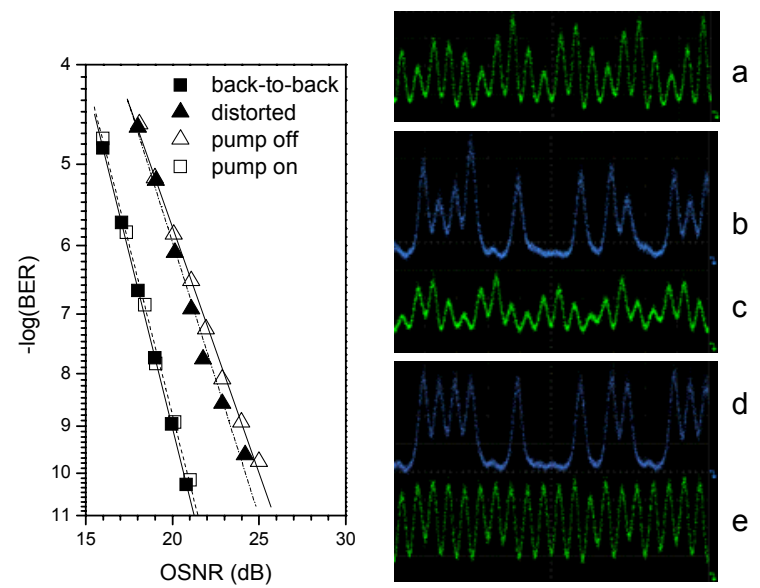

Figure 4: BER curves and patterns a): after distortion; b),c): at FOPA output with pump off; d),e): at FOPA output with pump on.

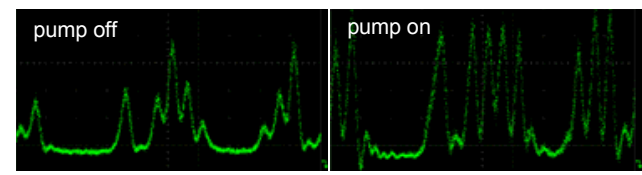

Figure 5: RZ-OOK waveforms at the FOPA output..

\section{Conclusion}

We have shown that single-pump FOPAs offer an increased input power dynamic range for RZ-DPSK modulation compared to RZ-OOK. This behaviour can be exploited to achieve intensity regeneration of RZDPSK signals in a FOPA with $22 \mathrm{~dB}$ gain, without being limited by SPM, as would be the case for RZOOK. The first unambiguous BER characterisation of a FOPA-based regenerator for amplitude equalisation of $40 \mathrm{Gbit} / \mathrm{s}$ RZ-DPSK signals was also presented.

EOARD is acknowledged for financial support.

\section{References}

1. M. Matsumoto, J. Lightwave Technol., 23 (2005) 2696-701.

2. K. Inoue, Electron. Lett., 36 (2000) 1016-7.

3. M. Matsumoto, OFC'06, JThB18.

4. N. Alic et al, Opt. Expr., 16 (2007) 8997-9008.

5. M. Sköld et al., OFC'08, OML4.

6. F. Futami et al., OFC'07, OThB3. 